\title{
Mode of anesthesia for cesarean delivery with pernicious placenta previa - a retrospective study
}

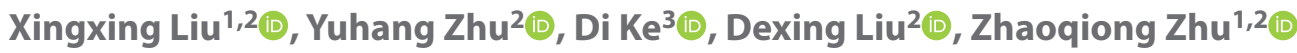 \\ 'Soochow University, Suzhou, China \\ ${ }^{2}$ Department of Anesthesiology, Affiliated Hospital of Zunyi Medical University, Zunyi, Guizhou, China \\ ${ }^{3}$ Department of Emergency, Affiliated Hospital of Zunyi Medical University, Zunyi, Guizhou, China
}

\begin{abstract}
Objectives: Anesthesia for cesarean delivery in parturients diagnosed with pernicious placenta previa remains controversial. This study aimed to review pernicious placenta previa cases to evaluate anesthetic management strategies.

Material and methods: This retrospective analysis included patients who underwent cesarean delivery (CD) for pernicious placenta previa at the Affiliated Hospital of Zunyi Medical University between December 1, 2012 and November 31, 2017. Patient demographic data, obstetric characteristics, anesthetic management, and maternal outcomes were extracted from the hospital's computerized database.

Results: In all, 61 consecutive cases of pernicious placenta previa were identified among 9512 cesarean deliveries. General anesthesia was performed on 27 of the 61 patients (44.3\%). Among GA group, 16 (59.3\%) had placenta accreta, 8 of whom required cesarean hysterectomy. Also, 13 of the 27 (48.1\%) GA patients required transfer to the intensive care unit. The other 34 patients (55.7\%) were given regional anesthesia, 9 of whom were converted to general anesthesia due to excessive bleeding and prolonged operation times. Statistical results indicated that regional anesthesia was associated with a significantly shorter operation time, less perioperative blood loss, fewer intraoperative red blood cell transfusions, and a lower incidence of complications.

Conclusions: Anesthetic management is important for parturients with pernicious placenta previa. Although regional anesthesia was our preferred method for these patients, general anesthesia is safe for patients with pernicious placenta previa who experience massive blood loss and prolonged operation times.
\end{abstract}

Key words: anesthesia; anesthetic techniques; obstetric; pernicious placenta previa; regional/general anesthesia

Ginekologia Polska 2020; 91, 2: 91-94

\section{INTRODUCTION}

Placenta accreta is 'more common' in patients with placenta previa and a history of prior cesarean delivery (CD). Concomitant pernicious placenta previa (PPP) can lead to unmanageable, massive hemorrhaging [1, 2]. PPP was first described by Chattopadhyay et al. in 1993 [3]. It refers to the placenta previa is anterior and implanted over the prior scar, irrespective of whether there is accreta, which is a post-delivery diagnosis $[4,5]$.

For the past decade in China, the incidence of PPP has gradually risen because of the increased rate of $C D$ and implementation of a more liberal two-child policy. It is a risk factor for abnormally invasive placentation, thereby increasing the number of hysterectomies performed. The reported blood loss during $C D$ for patients with PPP is $3000-5000 \mathrm{~mL}$ and the rate of hysterectomy rate $55-75 \%[6,7]$.

The number of patients with PPP admitted to our hospital is increasing every year. It is a necessary but difficult challenge for anesthesiologists to achieve good anesthesia management. The choice of anesthesia for such patients is a controversial, and the whether general anesthesia (GA) or regional anesthesia (RA) is unknown. Many anesthetists prefer GA to RA as they wish to avoid the risk of excessive bleeding and shock that may ensue with RA [8]. Thus, there has been extensive administration of GA for cesarean delivery whenever placenta previa was the indication for $C D$. The association of placenta previa with antepartum hemorrhage and the possibility of cesarean hysterectomy in these patients often prompts the choice of $\mathrm{GA}$ for $\mathrm{CD}$, although 
there is evidence that views may be changing. There has been an increase in the use of RA for placenta previa because of the assertion that the regional technique remains the safer option $[9,10]$. There is little evidence, however, regarding the choice of anesthetic technique for $\mathrm{CD}$ in pregnancies complicated by PPP, especially in the presence of placenta accreta.

Because PPP is a serious, life-threatening condition resulting in significant maternal and perinatal morbidity and mortality, it is clinically relevance to evaluate mode of anesthesia utilized and whether mode of anesthesia impacts maternal outcome. We therefore performed a retrospective analysis to assess obstetric anesthesia management, including the choice of anesthesia and maternal outcomes, among parturients with PPP during a 5-year period at our university hospital.

\section{MATERIAL AND METHODS}

This study was approved by the institutional ethics committee of the Affiliated Hospital of Zunyi Medical University. Informed consent was waived owing to the retrospective nature of the study design. We performed a retrospective analysis of 61 parturients who underwent CD between December 1, 2012 and November 1, 2017 at our hospital for PPP. Inclusion criteria included (1) placenta previa, (2) at least 1 prior $C D$, (3) ultrasonographic evidence of placental attachment to the uterine scar. Patients for whom there were insufficient data were excluded.

The following information, extracted from the hospital's computerized database, was recorded for each patient: age, gestational age, gravidity, parity, number of prior CDs, antepartum hemorrhage, emergency vs. elective surgery, mode of anesthesia, concurrence of placenta accreta by (visual or pathological confirmation), prophylactic placement of internal iliac artery balloon catheters, intraoperative blood salvage, estimated blood loss during surgery, amount of red blood cells transfused, preoperative and postoperative hemoglobin levels, Apgar score, hysterectomy, duration of surgery, admission to the intensive care unit, intraoperative and postoperative complications, length of hospital stay.

Statistical analyses were performed using Statistical Package for Social Sciences (SPSS ${ }^{\mathrm{TM}}$ ), Windows version 23.0 (IBM Corp., Armonk, NY, USA). Because of the lack of agreement with normal distributions, the demographic data and obstetric characteristics are presented as medians (range) or numbers (\%). The quantitative data were analyzed by the Mann-Whitney $U$ test. Qualitative data were compared between groups using the $\chi^{2}$ test. For statistical tests, a value of $p<0.05$ was considered to indicate statistical significance.

\section{RESULTS}

Among 9512 CDs recorded during the 5-year analysis, 61 consecutive patients with PPP met the inclusion criteria and underwent CD. The incidence of PPP among all CDs was $6.4 \%$ o. Table 1 shows demographics of the population studied. The most common reason for admission was antepartum hemorrhage $(n=39)$. Altogether, $47(77.05 \%)$ patients were admitted under emergency conditions.

In total, general anesthesia (GA) was utilized in 27 cases (44.26\%) and regional anesthesia (RA) performed in 34 cases (55.74\%). Of 34 cases under RA, 9 (14.75\%) were converted to GA due to excessive bleeding, prolonged operative times, or both. Four patients required placement of internal iliac artery balloon catheters, and nine underwent intraoperative blood salvage.

Perioperative anesthesia management is outlined in Table 2 . There were no differences between the two anesthesia groups regarding patient age; numbers of pregnancies, $C D$, or emergency cases; and baseline hemoglobin concentrations. GA was performed in 27 (44.3\%) patients. More than half of these patients $(16 / 27,56.3 \%)$ had placenta accreta, and 8 of the 16 underwent cesarean hysterectomy. Among the 27 GA patients, 13 (48.1\%) were transferred to the intensive care unit. RA was associated with higher 1-min Apgar scores and higher postoperative hemoglobin levels. Estimated blood loss was less and transfusion was required less frequently in the RA group than in the GA group.

Intraoperative and postoperative complications are summarized in Table 3. All of the women survived with no serious long-term sequelae. Two in the GA group sustained

\begin{tabular}{|c|c|}
\hline Characteristic & Outcome \\
\hline Age [years], median (range) & $31(22-40)$ \\
\hline Gestational age [weeks], median (range) & $35(28-40)$ \\
\hline \multicolumn{2}{|l|}{ Gravidity, n (\%) } \\
\hline 1 & $0(0)$ \\
\hline 2 & $8(13.1)$ \\
\hline 3 & $19(31.2)$ \\
\hline 4 & $21(34.4)$ \\
\hline 4 & $13(21.3)$ \\
\hline \multicolumn{2}{|l|}{ Parity, n (\%) } \\
\hline 1 & $48(78.7)$ \\
\hline 2 & $11(18.0)$ \\
\hline 3 & $2(3.28)$ \\
\hline \multicolumn{2}{|l|}{ Number of prior CDs, $\mathrm{n}(\%)$} \\
\hline 1 & $52(85.2)$ \\
\hline 2 & $9(14.8)$ \\
\hline Antepartum hemorrhage, $\mathrm{n}(\%)$ & $39(63.9)$ \\
\hline Elective CD, n (\%) & $14(23.0)$ \\
\hline Emergency CD, n (\%) & $47(77.0)$ \\
\hline
\end{tabular}




\begin{tabular}{|c|c|c|}
\hline Clinical feature & $\begin{array}{l}\text { General } \\
\text { anesthesia } \\
(\mathbf{n}=27)\end{array}$ & $\begin{array}{l}\text { Regional } \\
\text { anesthesia } \\
(\mathrm{n}=34)\end{array}$ \\
\hline Emergency cases, n (\%) & $23(85.2)$ & $24(70.6)$ \\
\hline Placenta accreta, n (\%) & $16(59.3)$ & $10(29.4)^{*}$ \\
\hline $\begin{array}{l}\text { Duration of surgery (min), } \\
\text { median (range) }\end{array}$ & $149(54-352)$ & $84(45-216)^{*}$ \\
\hline $\begin{array}{l}\text { Estimated blood loss, mL, } \\
\text { median (range) }\end{array}$ & $\begin{array}{l}3219 \\
(300-14000)\end{array}$ & $\begin{array}{l}1029 \\
(300-3500)^{*}\end{array}$ \\
\hline \multicolumn{3}{|l|}{ Blood product transfusion (median) } \\
\hline RBC required, $\mathrm{n}(\%)$ & $27(100)$ & $25(73.5)^{*}$ \\
\hline Red blood cells (units) & $8.3(1.5-26)$ & $2.3(0-6)^{*}$ \\
\hline \multicolumn{3}{|l|}{ Intraoperative blood salvage } \\
\hline Number of cases, $n(\%)$ & $7(25.9)$ & $2(5.9)$ \\
\hline The amount, $\mathrm{mL}$, median (range) & $607(0-2500)$ & $350(0-700)$ \\
\hline \multicolumn{3}{|c|}{ Hemoglobin concentration, median (range) } \\
\hline Preoperative values $[\mathrm{g} / \mathrm{L}]$ & $103(71-137)$ & $107(61-131)$ \\
\hline Postoperative values[g/L] & $90(71-127)$ & $97(71-121)^{*}$ \\
\hline \multicolumn{3}{|l|}{ Apgar Score } \\
\hline $1 \mathrm{~min}$ & $7(1-10)$ & $9(4-10)^{*}$ \\
\hline $5 \mathrm{~min}$ & $9(3-10)$ & $10(8-10)^{*}$ \\
\hline Caesarean hysterectomy, n (\%) & $12(44.4)$ & $1(2.9)^{*}$ \\
\hline Admission to intensive care unit, $\mathrm{n}(\%)$ & $13(48.1)$ & $0(0)^{*}$ \\
\hline
\end{tabular}

Data are presented as: number of patients $(n)$ and percentage (\%), or median (range); ${ }^{*} p<0.05$ for women with regional anesthesia versus general anesthesia group

ureteral injuries, which were repaired without difficulty. One of these two women had a postoperative wound infection, and the other had a urinary tract infection. Among the $27 \mathrm{GA}$ patients, 14 (51.9\%) had a fever postoperatively.

\section{DISCUSSION}

Pernicious placenta previa (PPP) is associated with an increased risk of antepartum bleeding, postpartum hemorrhage, hysterectomy, and need for blood transfusion. Most studies report that the risk of placenta previa increases proportionately with the number of prior CDs [11-14]. The association between placenta previa and prior uterine scarring greatly increases the chance of developing placenta accreta. In the present study, the incidence of placenta accreta was $42.6 \%$. Additionally, as the number of CD increased, the risk of the patient having PPP increased.

The optimal anesthesia technique for $C D$ in women with PPP is controversial and clinically challenging for the anesthesiologist.

What constitutes the best anesthesia technique for $C D$ in women with PPP is controversial, comprising a clinical dilemma for anesthetists. Kocaoglu et al.[8] advocate GA over

\begin{tabular}{|c|c|c|}
\hline Complication & $\begin{array}{l}\text { General } \\
\text { anesthesia } \\
(\mathbf{n = 2 7 )}\end{array}$ & $\begin{array}{l}\text { Regional } \\
\text { anesthesia } \\
(n=34)\end{array}$ \\
\hline \multicolumn{3}{|l|}{ Intraoperative complications, n (\%) } \\
\hline Ureteral injury & $2(7.4 \%)$ & $0(0)$ \\
\hline Bowel injury & $0(0)$ & $0(0)$ \\
\hline \multicolumn{3}{|l|}{ Postoperative complications, n (\%) } \\
\hline Wound infection & $1(3.7 \%)$ & $1(2.9 \%)$ \\
\hline Urinary tract infection & $1(3.7 \%)$ & $0(0)$ \\
\hline Repeat laparotomy required, n (\%) & $2(7.4 \%)$ & $0(0)$ \\
\hline Febrile morbidity, n (\%) & $14(51.9)$ & $2(5.9 \%)^{*}$ \\
\hline Mortality, n (\%) & $0(0)$ & $0(0)$ \\
\hline $\begin{array}{l}\text { Days in hospital [days], } \\
\text { median (range) }\end{array}$ & $13(4-39)$ & $10(5-27)$ \\
\hline
\end{tabular}

Data are presented as: number of patients ( $\mathrm{n}$ ) and percentage (\%), or median (range); ${ }^{*} p<0.05$ for women with regional anesthesia versus general anesthesia group

RA for women with placenta previa to lower the incidence of bleeding. Parekh and colleagues [10] report greater use of RA compared to GA for such cases (60\%) and advocate RA was associated with a significantly reduced estimated blood loss and reduced need for blood transfusion. Hong et al. [15] compared epidural anesthesia and GA in women undergoing $C D$ for placenta previa. They found that GA resulted in lower immediate postoperative hematocrit levels. Also, the GA patients required significantly more transfusions than patients given epidural anesthesia. The authors concluded that epidural anesthesia is superior to GA for elective $C D$ performed for placenta previa with regard to maternal hemodynamics and blood loss [15]. In a multi-institutional study, Chestnut et al. [16] found that none of the patients with continuous epidural anesthesia for elective or emergency peripartum hysterectomy required intraoperative induction of GA.

During the past 5 years at our institution, 27 parturients received $G A, 16$ of whom were complicated with placenta accreta, with $85 \%$ of them emergency cases. More than half of our patients (55.7\%) underwent RA. Our data show that either GA or RA could be used for CD in women with PPP.

The main concerns with the use of RA for PPP by anesthetists are as follows. First, cardiovascular reflexes are impaired in all patients under extensive regional block, which may be made worse in the event of significant intraoperative hemorrhage in patients with PPP, especially those complicated with placenta accreta. Second, anesthetic management of serious bleeding in awake patients is difficult for the anesthetist and may worry the patient. These concerns can be reduced in the patients who are not actively bleeding. Well-conducted RA should improve outcomes [17]. 
In the retrospective analysis, mode of anesthesia was variable and likely depended on the CD indication, urgency, and the maternal volume status. Even in patients with suspicion for placenta accreta, RA use was uneventful in less urgent cases in which pre-delivery volume status was not compromised. If hemorrhaging occurs intraoperatively and the patient becomes hemodynamically unstable, conversion to GA may be necessary. Among the 61 parturients in this study, 9 required conversion from RA to GA. Those who received $G A$, whether primary or by conversion from $\mathrm{RA}$, had greater blood loss, greater transfusion requirement, and lower postoperative anemia. We cannot distinguish between selection bias and any true association between use of GA and these higher morbidity outcomes.

For women with PPP and suspected placenta accreta, surgical management can be difficult and requires multidisciplinary efforts to minimize maternal complications. Some suggest preoperative placement of balloon catheters in the internal iliac arteries, which could potentially decrease blood loss and provide optimum exposure of the operative field [18]. Among our 61 patients, 4 (6.6\%) underwent prophylactic placement of internal iliac artery balloon catheters. Our institution initiated use of the technique last year, and the current evidence is based on small retrospective studies. Large studies or randomized controlled trials are needed to demonstrate the efficacy of prophylactic placement of internal iliac artery balloon catheters.

PPP can cause serious bleeding. The largest blood loss from a single patient in our group was $14,000 \mathrm{~mL}$. Intraoperative blood salvage has been used in obstetric patients. For this purpose, during $C D$ after placental delivery, blood is suctioned from the surgical site, collected, and processed through a cell-salvage machine that yields a washed red blood cell product for transfusion. To date, no prospective randomized studies have evaluated the safety of intraoperative blood salvage in obstetrics, although the review of more than 400 case reports by Allam et al. [19] reveal no complications leading to poor maternal outcomes that were directly attributable to the use of this technique. Moreover, Goucher et al. [20] stated that cell salvage is cost-effective in patients with predictably high rates of transfusion. There were no complications in our nine patients who underwent intraoperative blood salvage.

In conclusion, we found that the incidence of PPP was $6.4 \%$ of all cesarean deliveries in our teaching hospital. We also found that the choice of anesthetic depends on the $C D$ indication and urgency as well as the maternal volume status. Also, RA could be used in patients with suspected placenta accreta. Finally, significant hemorrhage is likely to require obstetric hysterectomy, and conversion to GA may be necessary.

\section{REFERENCES}

1. Zhu B, Yang K, Cai L. Discussion on the Timing of Balloon Occlusion of the Abdominal Aorta during a Caesarean Section in Patients with Pernicious Placenta Previa Complicated with Placenta Accreta. Biomed Res Int. 2017; 2017: 8604849, doi: 10.1155/2017/8604849, indexed in Pubmed: 29230417.

2. Huang S, Xia A, Jamail G, et al. Efficacy of temporary ligation of infrarenal abdominal aorta during cesarean section in pernicious placenta previa. Zhong Nan Da Xue Xue Bao Yi Xue Ban. 2017; 42(3): 313-319, doi: 10.11817/j.issn.1672-7347.2017.03.013, indexed in Pubmed: 28364106.

3. Chattopadhyay SK, Kharif H, Sherbeeni MM. Placenta praevia and accreta after previous caesarean section. Eur J Obstet Gynecol Reprod Biol. 1993; 52(3): 151-156, doi: 10.1016/0028-2243(93)90064-j, indexed in Pubmed: 8163028.

4. Obstetrics and Gynecology. 8th ed. Peoples Medical Publishing House, Beijing 2013: 126-127.

5. Chen Z, Li Ju, Shen J, et al. Direct puncture embolization of the internal iliac artery during cesarean delivery for pernicious placenta previa coexisting with placenta accreta. Int J Gynaecol Obstet. 2016; 135(3): 264-267, doi: 10.1016/j.ijgo.2016.05.018, indexed in Pubmed: 27634053.

6. Angstmann T, Gard G, Harrington T, et al. Surgical management of placenta accreta: a cohort series and suggested approach. Am J Obstet Gynecol. 2010; 202(1): 38.e1-38.e9, doi: 10.1016/j.ajog.2009.08.037, indexed in Pubmed: 19922901.

7. Hull AD, Moore TR. Multiple repeat cesareans and the threat of placenta accreta: incidence, diagnosis, management. Clin Perinatol. 2011; 38(2): 285-296, doi: 10.1016/j.clp.2011.03.010, indexed in Pubmed: 21645796.

8. Kocaoglu N, Gunusen I, Karaman S, et al. Management of anesthesia for cesarean section in parturients with placenta previa with/without placenta accreta: a retrospective study. Ginekol Pol. 2012; 83(2): 99-103, indexed in Pubmed: 22568353.

9. Imarengiaye CO, Osaigbovo EP, Tudjegbe SO. Anesthesia for cesarean section in pregnancies complicated by placenta previa. Saudi Med J. 2008; 29(5): 688-691, indexed in Pubmed: 18454215.

10. Parekh N, Husaini SW, Russell IF. Caesarean section for placenta praevia: a retrospective study of anaesthetic management. Br J Anaesth. 2000; 84(6): 725-730, doi: 10.1093/oxfordjournals.bja.a013582, indexed in Pubmed: 10895745.

11. Clark SL, Koonings PP, Phelan JP. Placenta previa/accreta and prior cesarean section. Obstet Gynecol. 1985; 66(1): 89-92, indexed in Pubmed: 4011075.

12. Ayaz A, Farooq MU. Risk of adverse maternal and peri-natal outcome in subjects with placenta previa with previous cesarean section. Kurume Med J. 2012; 59(1-2): 1-4, doi: 10.2739/kurumemedj.59.1, indexed in Pubmed: 23257632.

13. Zaki ZM, Bahar AM, Ali ME, et al. Risk factors and morbidity in patients with placenta previa accreta compared to placenta previa non-accreta. Acta Obstet Gynecol Scand. 1998; 77(4): 391-394, indexed in Pubmed: 9598946.

14. To WW, Leung WC. Placenta previa and previous cesarean section. Int J Gynaecol Obstet. 1995; 51(1): 25-31, doi: 10.1016/0020-7292(95)80004$\mathrm{V}$, indexed in Pubmed: 8582514.

15. Hong JY, Jee YS, Yoon HJ, et al. Comparison of general and epidural anesthesia in elective cesarean section for placenta previa totalis: maternal hemodynamics, blood loss and neonatal outcome. Int J Obstet Anesth. 2003; 12(1): 12-16, doi: 10.1016/s0959-289x(02)00183-8, indexed in Pubmed: 15676315 .

16. Chestnut DH, Dewan DM, Redick LF, et al. Anesthetic management for obstetric hysterectomy: a multi-institutional study. Anesthesiology. 1989; 70(4):607-610, doi: 10.1097/00000542-198904000-00009, indexed in Pubmed: 2648896.

17. Imarengiaye CO, Osaigbovo EP, Tudjegbe SO. Anesthesia for cesarean section in pregnancies complicated by placenta previa. Saudi Med J. 2008; 29(5): 688-691, indexed in Pubmed: 18454215.

18. Angileri SA, Mailli L, Raspanti C, et al. Prophylactic occlusion balloon placement in internal iliac arteries for the prevention of postpartum haemorrhage due to morbidly adherent placenta: short term outcomes. Radiol Med. 2017; 122(10): 798-806, doi: 10.1007/s11547-0170777-z, indexed in Pubmed: 28551762.

19. Allam J, Cox M, Yentis SM. Cell salvage in obstetrics. Int J Obstet Anesth. 2008; 17(1): 37-45, doi: 10.1016/j.ijoa.2007.08.001, indexed in Pubmed: 18162201.

20. Goucher H, Wong CA, Patel SK, et al. Cell Salvage in Obstetrics. Anesth Analg. 2015; 121(2): 465-468, doi: 10.1213/ANE.0000000000000786, indexed in Pubmed: 26197375. 